Federal Reserve Bank of Minneapolis Research Department

\title{
Exhuming Q: Market Power vs. Capital Market Imperfections
}

\author{
Russell Cooper and João Ejarque* \\ Working Paper 611
}

January 2001

\begin{abstract}
Evidence of the statistical significance of profits in Q regressions remains one of the principal findings in the empirical investment literature. This result is frequently taken to support the view that capital market imperfections are an important element for understanding investment. This paper challenges that conclusion. We argue that allowing the profit function at the firm level to be strictly concave, reflecting, for example, market power, is sufficent to replicate the $\mathrm{Q}$ theory based regression results in which profits are a significant factor determining investment. To be clear, our ability to replicate the existing results does not require the specification of any capital market imperfections. Thus the friction that explains the statistical significance of profits could be market power by sellers rather than capital market imperfections.
\end{abstract}

${ }^{*}$ Cooper, Boston University and Federal Reserve Bank of Minneapolis; Ejarque, University of Copenhagen. We are grateful to the NSF for financial support and to Jean-Pascal Benassy, Simon Gilchrist, Fumio Hayashi, Charles Himmelberg, Peter Klenow, John Leahy, Fabio Schiantarelli, and Jon Willis for comments on this research. Jon Willis provided outstanding research assistance. Joyce Cooper takes full responsibility for the title of this paper. The views expressed herein are those of the authors and not necessarily those of the Federal Reserve Bank of Minneapolis or the Federal Reserve System. 


\section{Motivation}

In the large empirical literature on models of capital accumulation, there is ample evidence that financial variables, such as profits, are significant regressors for current investment. $^{1}$ The empirical finding of significant profits often appears in empirical investment studies based upon "Q theory". This findings have been very influencial: they appear to underlie the position that capital market frictions are necessary to explain observed investment behavior.

The basic idea of $\mathrm{Q}$ theory is to solve the dynamic optimization problem of a firm with convex costs of capital adjustment. The firm will optimally weigh the current marginal costs of investment against the future marginal returns. Under some assumptions (essentially homogeneity restrictions on the profit and adjustment cost functions), this marginal gain can be proxied for by the value of the firm relative to its capital stock, a value called "average Q". The power of this approach to investment is that an observeable, average Q, completely summarizes the expected discounted present value of additional investment. Under this theory: current profits should not explain current investment.

To many economists, the finding that profit measures are significant in investment regressions is taken as prima facie evidence of capital market imperfections. Thus these results provide motivation for numerous theories of credit frictions. Further, the statistical significance of profits, along with the large costs of adjustment generally found in these empirical papers have lead to the conclusion that the Q-theory approach is an empirical failure.

\footnotetext{
${ }^{1}$ Surveys of this literature are numerous. See, for example, the discussion in Chirinko [1993] and Caballero [1997] and the references therein. Noteworthy recent papers discussing this evidence are Gilchrist and Himmelberg [1995, 1999], Cummins, Hasset and Oliner [1999] and Erickson-Whited [2000].
} 
This paper argues that these conclusions may not be warranted. Much of the existing empirical work rests upon the substitution of average Q in place of marginal Q since the former is observable. However, this is appropriate only under very strict assumptions concerning the profit and cost of adjustment functions. Our analysis studies investment models which do not satisfy the Q-theory assumptions: firms may have market power as sellers. ${ }^{2}$ Hence, marginal and average $\mathrm{Q}$ are not identical so that empirical models using average $\mathrm{Q}$ are misspecified. Potentially this misspecification can "explain" the failures of the Q model. ${ }^{3}$ Specifically, this paper addresses the following question: can the significance of profit flows found in Q-based investment regressions be explained by an empirically relevant model without capital market imperfections? ${ }^{4}$ Further, can this model also explain the large estimated adjustment costs?

The difficult aspect of addressing these questions is the lack of analytic results for the types of investment models we wish to study: i.e. those in which the specification of technology and adjustment costs do not satisfy the restrictions of Q theory. Evaluation of models outside of the Q-framework is difficult empirically since these alternatives are not easily reduced to simple linear relationships. ${ }^{5}$

\footnotetext{
${ }^{2}$ The fact that marginal and average $\mathrm{Q}$ will diverge when firms have market power is discussed by Hayashi [1982, Proposition 2]. Galeotti and Schiantarelli [1991] estimate an investment model allowing for market power and find support for it Their analysis, however, does not attempt to "explain" the findings in the more traditional Q theory based empirical literature.

Hayashi and Inoue [1991] estimate a Q model for Japanese firms and argue that the model may fit the light industry firms poorly, with cash flow significant, because these firms have market power.

${ }^{3}$ The recent contribution of Erickson-Whited [2000] also focuses on measurement errors. However, their analysis introduces measurement error into Tobin's Q but maintain conditions such that average and marginal $\mathrm{Q}$ are the same though they recognize that violations of these assumptions could influence the inference. On this, see the discussion on pg. 1036-37 of Erickson-Whited [2000]. Our approach, in contrast, is to relax assumptions of homogeneity in the profit function and thus allow for a gap between average and marginal Q.

${ }^{4}$ We use the term "empirically relevant" here to constrain our search for parameterizations that are not at variance with other investment facts.

${ }^{5}$ Tractability, of course, is one of the arguments in favor of the linear quadratic structure. Our findings indicate the cost of this simplication: results based upon this structure may be misleading.
} 
Our empirical approach is structural in nature. We analyze a dynamic programming problem for a firm with market power which we solve numerically and compare to the data. We estimate relevant parameters by comparing the moments generated by our simulated model with the data. In particular, we use an indirect inference approach so that the parameters of our models are selected to match observed Q-theory regressions augmented by cash flow measures. ${ }^{6}$ This is a methodological innovation that complements the more general approach we are taking to understanding investment.

Our findings are first that with the addition of a reasonable amount of curvature in profit functions, one can reproduce the regression results commonly found in the Q theory based empirical investment literature. In particular, profits enter the regression significantly and with a coefficient close to that reported by others without the introduction of borrowing restrictions into the firm's optimization problem. Second, the parameterization of the quadratic adjustment costs function is quite reasonable: the estimated cost of adjustment function is close to the quadratic model. ${ }^{7}$ Third the level of adjustment costs is much lower than that inferred by other researchers. Finally, we find that our unconstrained model can also match empirical results based upon sample splits which were intended to partition the sample into constrained and unconstrained firms. In our results, no firms are constrained and differences between "large" and "small" firms reflect small differences in adjustment costs and other parameters.

\footnotetext{
${ }^{6}$ This approach is presented in Gourieroux, and Monfort [1996], Gourieroux, Monfort and Renault [1993]. Cooper and Haltiwanger [2000] use this approach to study investment with nonconvex costs of adjustment. Adda and Cooper [2000] use a structural estimation approach to study the impact of scrapping subsidies on new car purchases. Willis [1999] estimates the distribution of price adjustment costs using indirect inference as well.

${ }^{7}$ However, our specification does not allow for nonconvex costs of adjustment as in, for example, Cooper and Haltiwanger [2000].
} 
Overall, our findings challenge the prevailing wisdom that Q theory based investment regressions support the view that firm's face borrowing restrictions. In fact, our results do not indicate that Q theory is alive and well: only that is has been buried for the wrong reasons.

\section{Dynamic Capital Accumulation}

Our approach to the neoclassical investment model is easily understood from examining a dynamic optimization problem in which a firm chooses the level of capital that maximizes the discounted expected value of its profits. ${ }^{8}$ The firm incurs adjustment costs when investing a nonzero amount. New capital is productive in the following period and depreciates at an exogenous rate, $\delta$.

Letting $K$ denote the current stock of capital, $A$, a shock to productivity or demand, $\pi(K, A)$ the profit level in state $(K, A), p$ the relative price of capital, the optimization problem can be expressed as a dynamic programming problem. ${ }^{9}$ The value function for the firm $V(K, A)$ solves:

$$
V(K, A)=\max _{K^{\prime}} \pi(K, A)-p\left(K^{\prime}-K(1-\delta)\right)-C\left(K^{\prime}, K\right)+\beta E_{A^{\prime} \mid A} V\left(K^{\prime}, A^{\prime}\right)
$$

Here $\pi(K, A)$ represents a reduced form profit function generated by the firm's solution over other, freely adjustable factors of production.

In this problem, the firms faces no borrowing constraints. For example, investment

\footnotetext{
${ }^{8}$ Out approach builds upon Lucas-Prescott [1971] though they restrict attention to a competitive framework.

${ }^{9}$ This representation of the firm's problem does ignore variations in the cost of capital which are more likely to be relevant for a time series analysis, as in Abel-Blanchard [1986], than for our study which is based largely on cross sectional variations.
} 
expenditures do not have to be financed out of current profits. The firm chooses tomorrow's capital $\left(K^{\prime}\right)$ using its conditional expectations of future profitability, $A^{\prime}$. Of course, to the extent that $A^{\prime}$ is correlated with $A$, current profits will be correlated with future shocks and thus informative about future profits.

Assuming that $V(K, A)$ exists, an optimal policy, denoted by $K^{\prime}=h(K, A)$ must satisfy:

$$
C_{K^{\prime}}\left(K^{\prime}, K\right)+p=\beta E_{A^{\prime} \mid A} V_{K^{\prime}}\left(K^{\prime}, A^{\prime}\right)
$$

where subscripts on the functions denote partial derivatives. The right side of this expression is conventionally termed "marginal Q" and denoted by $q$. Note the timing: the appropriate measure of marginal $\mathrm{Q}$ is the expected discounted marginal value of capital in the following period due to the one-period investment delay. Using (1), this expression can be simplified to an Euler equation:

$$
C_{K^{\prime}}\left(K^{\prime}, K\right)+p=\beta\left\{E_{A^{\prime} \mid A} \pi_{K}\left(K^{\prime}, A^{\prime}\right)+p(1-\delta)-C_{K^{\prime}}\left(K^{\prime \prime}, K^{\prime}\right)\right\} .
$$

The difficult aspect of this theory is its empirical implementation. As the value function and hence its derivative is not observable, (2) cannot be directly estimated. Thus the theory is tested either by finding a suitable proxy for the derivative of $V(K, A)$ or by estimating the Euler equation, (3). We focus here exclusively on estimates based upon using the average value of the firm as a substitute for the marginal value of an additional unit of capital. $^{10}$

\footnotetext{
${ }^{10}$ Given the prominence of this approach in the literature, it is natural to focus our analysis on these results.
} 


\section{A. Q Models}

The traditional Q theory model places additional structure on (1). In particular, following Hayashi [1982], assume that: $\pi(K, A)$ is proportional to $K$, and that the cost of adjustment function is quadratic:

$$
C\left(K^{\prime}, K\right)=\frac{\gamma}{2}\left(\frac{K^{\prime}-(1-\delta) K}{K}\right)^{2} K
$$

With this specification, one can show that $V(K, A)$ is proportional to $K$ so that marginal $q$ equals $V(K, A) / K$, a term that is called "average Q" and denoted here as $\bar{q} .{ }^{11}$

Using this relationship between average and marginal Q, (2) implies that the investment rate is a linear function of the expected value of future $\bar{q}$. Note that the theory implies that $\bar{q}$ contains all the information necessary to determine the firm's optimal investment. In particular, the theory does not suggest that past investment rates or any measures of current profits and/or financial variables are needed to ascertain the optimal investment plan for the firm.

\section{B. General Profits and Cost of Adjustment Functions}

This section returns to the more general dynamic capital accumulation problem given in (1) without the added restrictions of $Q$ theory. Instead of assuming current profits are linear in capital, as required by the $Q$ theory model, consider

$$
\pi(K, A)=A K^{\alpha}
$$

\footnotetext{
${ }^{11}$ The argument follows Lucas-Prescott [1971] and Hayashi [1982]. Note that the quadratic adjustment cost is sufficient, homogeneity of the adjustment cost function is necessary.
} 
where $\alpha$ parameterizes the curvature of the profit function. This curvature most naturally reflects market power by the seller. Further, we suppose that $C\left(K^{\prime}, K\right)$ is given by:

$$
C\left(K^{\prime}, K\right)=(\gamma / \theta)\left(\frac{K^{\prime}-(1-\delta) K}{K}\right)^{\theta} K
$$

This is a slight generalization of the quadratic cost of adjustment though it is still homogenous in $(I, K)$.

The key step away from the traditional $Q$ model is simply allowing $\alpha<1$. Hayashi [1982] demonstrates that in this case marginal $Q$ is always less than average $Q$. So, the curvature of the profit function creates a measurement error in the standard investment regression model as there is a gap between average and marginal $Q$ due to the strict convavity of the profit function.

The extension to non-quadratic costs of adjustment has a similar motivation. While the quadratic case, when combined with homogeneity assumptions, clearly makes the investment problem tractable, there is clearly no a priori logic for this curvature assumption. Our methodology allows us to explore more general specifications and thus to evaluate the quadratic restriction. ${ }^{12}$

\section{Empirical evidence}

There are numerous surveys of the investment literature with appropriate emphasis on results using average $Q$ as a proxy for marginal $Q$. Here we focus on empirical evidence

\footnotetext{
${ }^{12}$ Abel and Eberly [1999] and Barnett and Sakellaris [1999] also allow for non-quadratic costs of adjustment. Further, there is a significant literature investigating the implications of nonconvex costs of adjustment, as in Caballero, Engel and Haltiwanger [1995], Cooper, Haltiwanger and Power [1999] and Cooper-Haltiwanger [2000]. Relatedly, Caballero-Leahy [1996] study the relationship between investment and Q in a nonconvex environment.
} 
using the $Q$ framework and then turn to estimation of our structural model.

\section{A. Evidence on $Q$ Models}

The theory predicts a very specific investment equation for the $Q$ theory models: the investment rates depends only on the expected value of average $Q \cdot{ }^{13}$ Letting it denote period $t$ observation for firm $i$, tests of $Q$ theory on panel data are frequently conducted using an empirical specification of:

$$
(I / K)_{i t}=a_{i 0}+a_{1} E \bar{q}_{i t+1}+a_{2}\left(\pi_{i t} / K_{i t}\right)
$$

The theory implies that the coefficient on expected average $Q, a_{1}$, should equal $1 / \gamma$. The constant term is allowed to pick up firm specific heterogeneity that may arise from differences in the adjustment processes across firms, as in Gilchrist and Himmelberg [1995]. Note that this specification includes the profit rate, $\left(\pi_{i t} / K_{i t}\right)$. In fact, $Q$ theory does not suggest the inclusion of profit rates in (6). Rather, this variable is included as a way of evaluating an alternative hypothesis in which the effects of financial constraints are not included in average $Q$. Hence researchers focus on the statistical and economic significance of $a_{2} \cdot{ }^{14}$

The results obtained using this approach have been mixed. Two "problems" have emerged: (i) the relatively high value of the adjustment cost parameter and (ii) the significance of profits or other financial variables as a regressor. ${ }^{15}$

\footnotetext{
${ }^{13}$ Again, the timing assumption is that there is a one-period delay associated with the delivery and installation of new capital. In some applications, new investment is assumed to be immediately productive so that the appropriate measure of average $\mathrm{Q}$ is the current one.

${ }^{14}$ Gomes [1998] makes an important point here: even if there are borrowing restrictions, they will appear in the value of the firm. Whether they are properly accounted for in average and marginal $Q$ is less clear and again depends on the homogeneity of the underlying profit and cost functions and on the nature of the borrowing restrictions.

${ }^{15}$ In fact, the view that these models "fail empirically" is commonly held. See the concise discussion in
} 
On the first, point, while specifications and thus estimates of the coefficients certainly vary across studies, it is not uncommon to find extremely low estimates of $a_{1}$ and thus an inference of large adjustment costs. In his original study of this model, Hayashi [1982], found $a_{1}=0.0423$. Abel and Blanchard [1986] obtain nonsignificant coefficients for contemporaneous average $Q$. Fazzari Hubbard and Petersen [1988] obtain extremely low coefficients (for example, $a_{1}=0.0065$ in one of their specifications) while Gilchrist and Himmelberg [1995] obtain an estimate for $a_{1}$ of 0.033 .

To appreciate the magnitude of the estimates, a coefficient of $a_{1}=0.05$ implies $\gamma=20$. With an adjustment cost function of $\frac{\gamma}{2}(I / K)^{2} K$, this implies an average adjustment cost of $10 *(\delta)^{2} K$, using the steady state restriction of $I=\delta K$. With $\delta=0.15$, we get an adjustment cost relative to the steady state capital stock of $22.5 \%$, which is very large. Put differently, $a_{1}=0.05$ implies a $6 \%$ adjustment in the first period, $50 \%$ within 8 periods and 23 periods until full adjustment, a fairly slow process. ${ }^{16}$

On the second point, many studies find that $a_{2}$ is positive and significantly different from zero which is a rejection of the $Q$ theory. For example, Fazzari, Hubbard and Petersen [1988] divide their panel into three classes of firms determined by the ratio of dividends to income. They report significant effects of cash flow on investment for all types of firms though firms with higher dividend/income ratios have smaller cash flow coefficients. ${ }^{17}$ However, their

Erickson and Whited [2000] for example. Other common results in Q regressions are that residuals are serially correlated and lagged variables are significant (Chirinko [1993], Abel and Blanchard [1986]). This is a further sign that the model is misspecified, see West [1998].

${ }^{16}$ This is derived from an experiment where $\alpha=0.7, \gamma=20, \delta=0.15, \theta=2, \beta=0.94$. There are two possible states where the transition matrix for Markov process has 0.9 on the diagonal. The firm is assumed to start at the steady state associated with the low state of probitability. The profitability shock then jumps to the high state. It takes 23 years to get to the high steady state.

These numbers change significantly (but not overwhelmingly) if we have $a_{1}=0.5$ or $\gamma=2$. Then $14 \%$ of the adjustment occurs in the initial period and $54 \%$ within 5 periods, up to 18 periods to full adjustment.

${ }^{17}$ See their Table 5, instrumental variable estimation results. Cash flow coefficients are 0.455 (0.029) for 
$\bar{R}^{2}$ measures fall dramatically from the low to the high dividend firms (from 0.53 to 0.19 ). Both the $Q$ variable and the cash flow variable explain more for the low dividend firms: apparently whatever makes cash flow more significant also makes $Q$ more significant.

Gilchrist and Himmelberg [1995] obtain stronger results in favor of financial frictions. One of the important aspects of the Gilchrist-Himmelberg study is their construction of a proxy for marginal $Q$. As they note, one of the problems interpreting the significance of cash flow variables in investment regressions is that these factors may be forecasting future profits rather than constraining current investment. Using their panel, they estimate forecasting equations for marginal $Q$ and argue that any remaining explanatory power of financial variables will reflect capital market imperfections. ${ }^{18}$ With this measure of $Q$, which they term "Fundamental Q", Gilchrist and Himmelberg report (see their Table 2) that for their full sample Fundamental $Q$ is not significant and cash flow is barely significant. ${ }^{19}$ However, for their sample splits, financial variables are insignificant for their "unconstrained" subsample and are sometimes significant for their "constrained" subsample.

Cummins, Hassett and Oliner [1999] take an alternative approach to separating the informational content of profit fluctuations. For their data set, they do report familiar findings in terms of standard $Q$ regressions. ${ }^{20}$ In particular, the response of investment rates to variations in average $Q$ are quite small (implying a large value of $\gamma$ ) and cash flow is a significant regressor. However, when they replace average $Q$ with their measure of $Q$ based

low ratios, $0.418(0.038)$ for middle ratios and 0.238 (0.010) for high ratios. Low ratios are defined as less than $10 \%$ for at least $80 \%$ of the sample observations, between $10 \%$ and $20 \%$, and more than $20 \%$.

${ }^{18}$ In doing so, they assume that the profit function is linearly homogenous of degree one.

${ }^{19}$ In contrast, for their regressions without cash flow measures, the coefficient on fundamental Q exceeded that from their results using Tobin's Q. Further, this coefficient was significantly different from zero.

${ }^{20}$ In particular, see their Table 5 . 
upon earnings expectations, financial variables are no longer significant.

\section{B. Empirical Implications of the More General Model}

Our perspective on these results is quite different. We argue here that the apparent failure of $Q$ theory stems from misspecification of the firm's optimization problem as it ignores market power. Suppose that the profit and/or cost functions did not satisfy the conditions specified in Hayashi [1982]. As a consequence, average and marginal $Q$ diverge so that the use of $\bar{q}_{i t}$ in the standard investment regression induces measurement error that may be positively correlated with profits. ${ }^{21}$ Hence one might find positive and significant $\mathrm{a}_{2}$ in (6) in a model without any capital market imperfections.

Consider a version of (1) using the profit and cost of adjustment functions given in (4) and (5). Our goal is to estimate the key parameters characterizing the profit and adjustment cost functions: $(\alpha, \theta, \gamma)$. The key question is whether empirically plausible profit and adjustment cost functions can reproduce the regression results from estimating (6).

Our methodology follows the indirect inference procedures described in Gourieroux and Monfort [1996] and Gourieroux, Monfort and Renault [1993]. This is a version of simulated method of moments in that the structural parameters are chosen to minimize the distance between moments generated by the data and those calculated from the simulated data. As the moments of the simulated data depend on the underlying structural parameters, minimizing this distance will, under certain conditions, provide consistent estimates of the structural parameters. The innovation associated with indirect inference is to use the coefficients of a reduced form regression to establish moments from the data and then to match these

\footnotetext{
${ }^{21}$ We do not attempt to characterize this measurement error analytically but use our simulated environment to understand its implications.
} 
coefficients from estimating the same regression off the simulated data. The reduced form coefficients from the regression on the simulated data will be close to those from the actual data at the "true" values of the structural parameters.

The appealing feature of this approach is that it allows a researcher interested in a structural model to link results explicitly to existing less structural empirical evidence. For our purposes, we use the results of Gilchrist-Himmelberg [1995] as representative of the $Q$ theory based investment literature. Denote their estimates of the investment relationship parameters,(6), by $\left(a_{1}^{*}, a_{2}^{*}\right)$. Further, they present evidence for their full sample and for sample splits based, for example, on firm size and/or the dividend behavior of a firm.

We initially focus on results from their pooled panel sample and then return to understanding their sample splits. At this stage, our goal is to understand the foundations of empirical results based upon Tobin's $Q$. For this specification, they estimate $a_{1}=.03$ and $a_{2}=.24 .^{22}$ As these results are based upon a panel data set, our simulation/estimation exercise will be conducted within a panel structure too. To do so, we decompose the shocks to profitability into two components: an aggregate shock common to all firms and a firm specific shock.

The aggregate shock process is taken from the Cooper-Haltiwanger [2000] analysis of profitability shocks in the LRD. We represent this process as a two-state Markov process with a symmetric transition matrix in which the probability of remaining in either of the two aggregate states is $.8 .^{23}$

\footnotetext{
${ }^{22}$ These estimates are reported in their Table 2. Note that these regressions included time dummies and were estimated in first differences to remove firm fixed effects. Since we have no fixed effects build into our model, we do not need to remove them and hence focus on regression results in levels.

${ }^{23}$ In fact, our estimates are not very sensitive to the aggregate shocks. Instead, the model is essentially estimated from the rich cross sectional variation, as in the panel study of Gilchrist-Himmelberg [1995].
} 


\section{Estimates of $(\alpha, \gamma)$}

Our initial estimation exercise assumes the quadratic cost of adjustment specification $(\theta=2)$ and focuses on estimating the curvature of the profit function $(\alpha)$ and the level of the adjustment $\operatorname{costs}(\gamma)$. So, the only variation from the standard $Q$ theory model is firm market power. In order to focus the initial estimation on these key parameters, we set other parameters at levels found in previous studies: $\delta=.15$ and $\beta=.95$. This leaves $(\alpha, \gamma)$ and the stochastic process for the firm-specific shocks to profitability as the parameters remaining to be estimated. We estimate both the serial correlation $(\rho)$ and the standard deviation $(\sigma)$ of the profitability shocks.

Our approach to estimation requires two pieces: solving the dynamic programming problem and then simulating a panel data set. For each value of the vector of parameters, $\Theta \equiv(\alpha, \gamma, \rho, \sigma)$, we solve the firm's dynamic programming problem, using value function iteration. In order to solve the dynamic programming problem at the firm level, conditional expectations need to be formed using the parameters of the stochastic process for the firm specific shocks, $(\rho, \sigma)$. The method outlined in Tauchen [1986] is used to create a discrete state space representation of the process for any $(\rho, \sigma)$. Since the estimation makes extensive use of the cross sectional properties of the panel data set, we allowed 16 elements in the state space for the idiosyncratic profitability shock. ${ }^{24}$

Once the dynamic programming problem is solved, a panel data set can be created by simulation using the estimated processes for the shocks and the policy functions derived from the solution of the dynamic programming problem. For the simulations, we assumed

\footnotetext{
${ }^{24}$ Allowing for finer grids for capital and the shocks or increasing the number of firms or years had no noticeable effect on our estimates.
} 
there were 400 firms and 50 years of data.

Given this data set, the $Q$ theory model is estimated and other relevant moments are calculated. The regression was of the same form as (6). Thus for each value of $\Theta$, we obtain estimates of the parameters of $(6)$, call them $\left(\hat{a}_{1}, \hat{a}_{2}\right)$, where we have ignored the constant term. Further, we use three other moments reported by Gilchrist-Himmelberg: the serial correlation of investment rates (.4), the standard deviation of profit rates (.3) and the average value of average $Q(3) .{ }^{25}$

Let $\Psi^{d}$ denote the vector moments from the data and $\Psi^{s}(\Theta)$ denote the corresponding moments from the simulated data, given the vector of parameters $\Theta$. For our problem,

$$
\Psi^{d}=\left[\begin{array}{llll}
.03 & .24 & .3 & 3
\end{array}\right]
$$

As in all moment matching exercises, a discussion of why these particular regression coefficients/moments were chosen to match is appropriate. Clearly, given the motivation of trying to understand the reduced form empirical evidence from investment regressions, coefficient estimates from (6) are obviously important to the exercise. The serial correlation of investment rates and the standard deviation of profit rates are necessary to pin down the parameters of the driving process. Finally, average $Q$ was included to guarantee that our estimates of the curvature of the profit function did not produce unreasonably high profit rates since average $Q$ is determined by the discounted present value of average profit rates. Beyond the economic relevance of these moments, it is also important that they are responsive

\footnotetext{
${ }^{25}$ The average value of average $Q$ and the standard deviation of the profit rate (measured as cash flow) comes from Table 6 in Gilchrist-Himmelberg [1995]. The serial correlation of the investment rate comes directly from Charles Himmelberg and we are grateful to him for supplying this calculation.
} 
to variations in the underlying parameters of our problem. This property was verified in our simulations and underlies the standard errors of our estimates.

We compute a statistic, $J(\Theta)$, defined as:

$$
J(\Theta)=\left(\Psi^{d}-\Psi^{s}(\Theta)\right)^{\prime} W\left(\Psi^{d}-\Psi^{s}(\Theta)\right)
$$

where $W$ is an estimate of the inverse of the variance-covariance matrix of $\Psi^{d} .{ }^{26}$ The estimate of $\Theta, \hat{\Theta}$, solves:

$$
\min _{\Theta} J(\Theta)
$$

The difficult aspect of this problem is in characterizing the highly nonlinear mapping from the structural parameters $\Theta$ to the objective function $J(\Theta)$. Note that this parameter vector is overidentified since we are trying to match two regression coefficients and three moments using only four parameters.

The second row of Table 1a presents our estimates of structural parameters and standard errors. ${ }^{27}$ At the value of $\hat{\Theta}$ given in the second row of Table 1a we are able to closely match $\Psi^{d}$,as indicated by Table $1 b .^{28}$

\footnotetext{
${ }^{26}$ We used a multi-stage procedure to estimate the parameters and to determine $W$. We first estimated the parameters assuming that $W$ was the identity matrix. This produces consistent estimates. We then simulated multiple panels using these estimated parameters and for each panel reestimated the basic Q regression and recalculated the moments. We then computed the variance-covariance matrix from these moments. This new estimate of $W$ was then used to reestimate the coefficients. This procedure was repeated until the parameter estimates did not change much. This same estimate of $W$ was used to compute the standard errors, following Gouriéroux and Monfort [1996,Chpt. 4]

${ }^{27}$ The computation of standard errors follows the description in Chapter 4 of Gourieroux and Monfort [1996].

${ }^{28}$ In Table 1 and throughout, IC stands for imperfect competition $(\alpha<1)$. GH95 refers to Gilchrist and Himmelberg [1995]. Quadratic adjustment costs are indicated by $\theta=2, \mathrm{sc}(\mathrm{I} / \mathrm{k})$ indicates the serial correlation of the investment rate, $\operatorname{std}(\pi / \mathrm{k})$ indicates the standard deviation of the profit rate, and $\bar{q}$ denotes average $\mathrm{Q}$.
} 


\begin{tabular}{|l|l|l|l|l|l|}
\hline \multicolumn{5}{|l|}{ Structural Parameters } \\
\hline & $\alpha$ & $\gamma$ & $\rho$ & $\sigma$ & $\theta$ \\
\hline GH95 & & & & & \\
\hline IC, $\theta=2$ & $.689(.011)$ & $.149(.016)$ & $.106(.008)$ & $.855(.04)$ & 2 \\
\hline
\end{tabular}

Table 1a

\begin{tabular}{|l|l|l|l|l|l|}
\hline & \multicolumn{5}{|c|}{ Reduced Form Coef. Estimates/Moments } \\
\hline & $a_{1}$ & $a_{2}$ & $\operatorname{sc} \frac{I}{K}$ & $\operatorname{std} \frac{\pi}{K}$ & $\bar{q}$ \\
\hline GH95 & .03 & .24 & .4 & .25 & 3 \\
\hline IC, $\theta=2$ & .041 & .237 & .027 & .251 & 2.95 \\
\hline
\end{tabular}

Table $1 b$

The model, with its four parameters, does a good job of matching four of the five estimates/moments. The model is unable to reproduce the high level of serial correlation in plant-level investment rates. This appears to be a consequence of the fairly low level of $\gamma$ which implies that adjustment costs are not very large.

In terms of interpreting our results, the estimated curvature of the profit function of .689 implies a markup of about $15 \%{ }^{29}$ This estimate of $\alpha$ and hence the markup is not

\footnotetext{
${ }^{29}$ Let $p=y^{-\eta}$ be the demand curve and $y=A k^{\phi} l^{(1-\phi)}$ the production function. Maximization of profit over the flexible factor, $l$, leads to a reduced form profit function, $\pi(k, A, w)$ where $w$ is the wage rate. The exponent on capital is $\frac{\phi(\eta-1)}{(1-\phi)(1-\eta)-1}$. With $\phi=.33$, we find $\eta=.1315$, implying a markup of about $15 \%$.
} 
at variance with other estimates in the literature. It $(\alpha)$ is larger than the curvature estimate reported by Cooper-Haltiwanger [2000] for their analysis of plant-level profit functions. Gilchrist and Himmelberg [1999] estimate the marginal profit function and, by our calculations, find a curvature of between .5 and $.8 .^{30}$ Galeotti and Schiantarelli [1991] find significant market power for firms and a markup of about 33\%. ${ }^{31}$ Finally, Hayashi and Inoue [1991] estimate a $Q$ model on Japanese manufacturing data and argue that "The poor performance of the $\mathrm{Q}$ model for light industry may be attributable to the fact that the market for this industry is mostly domestic and more or less protected from international competition." 32

The other interesting parameter is our estimate of the level associated with the quadratic cost of adjustment, $\gamma$. As noted above, under the null of $Q$ theory, this parameter is the inverse of the coefficient on average $Q$ in the investment regression. Hayashi initially estimated this parameter at about 20. Subsequent work has led to lower estimates, including that produced by Gilchrist and Himmelberg [1995] who find parameter estimates as high as .33 and thus $\gamma=3$ for their "unconstrained firms". ${ }^{33}$

An interesting point from our results is that the estimate of $\gamma$ is not identified from the regression coefficient on average $Q$. While this inference is correct when the profit function exhibits constant returns to scale, it is not true when the function is strictly concave. In fact, the estimated value of $\gamma=.149$ is far from the inverse of the coefficient on average $Q$ (about

\footnotetext{
${ }^{30}$ If one uses cash flow their estimates using sales imply (see their footnote 10) a mean value of 0.76 and a range of 0.25 to 1.88 , and if one uses operating income one gets a mean value of 0.49 and a range of 0.16 to 1.17 .

${ }^{31}$ This estimate is based upon their discussion of their Table 1 estimates.

${ }^{32}$ Though they assume a perfectly competitive firm, they go on to note that "Cash flow can be significant because of its correlation with monopoly rent." Our results confirm these views. In fact, this suggests an exercise of looking cross sectionally at markups and regression coefficients from the $Q$ model. We are grateful to Peter Klenow for discussions of this point.

${ }^{33}$ Note though that this result does not come from a regression with Tobin's $Q$. So, the inference from the standard $Q$ theory, which requires average and marginal $Q$ to be equal, does not apply here.
} 
$4)$.

Thus, in the presence of market power, we see: (i) why profits are significant in the standard $Q$ regression and (ii) that actual adjustment costs are much smaller than those inferred under the standard $Q$ regression. Essentially, the misspecification of (1) by assuming perfect competition creates a measurement error in the standard $Q$ investment model as average and marginal $Q$ are not the same. It is this measurement error that lies at the heart of these results. ${ }^{34}$

\section{Sample Splits}

The large empirical $Q$ literature also distinguishes between firms that are likely to be constrained in financial markets and those that are not. One distinction is often made between large and small firms with the presumption being that the former are less likely to be constrained. Since there is no model of credit market frictions contained in most of these papers, the fact that large and small firms behave differently is not "explained". This is particularly troublesome given the constant returns to scale environment which implies that size should not matter.

An interesting issue is whether our model can explain differential findings by firm size. In Table 2 we report regression results from Gilchrist-Himmleberg [1995] for their large and small firm splits, as well as our estimation results. Using their discussion of the data, we assume that the serial correlation of investment rates, the standard deviation of profit rates and average $Q$ do not vary by firm size. ${ }^{35}$ As in Table 1, we report the structural parameter

\footnotetext{
${ }^{34}$ Another way to see this point is to note that if one regresses investment rates on average $Q$, the regression errors (which contain investment fluctuations not explained by average $Q$ ) are positively correlated with profit rates. This does not arise when we regress investment rates on a measure of marginal $Q$.

${ }^{35}$ This point is made in the Appendix of Gilchrist-Himmelberg [1995].
} 
estimates as well as the moments for each of two samples in Tables $2 \mathrm{a}$ and $2 \mathrm{~b} .^{36}$ Note that here we again impose the quadratic cost of adjustment.

\begin{tabular}{|l|l|l|l|l|l|}
\hline \multicolumn{5}{|l|}{ Structural Parameters } \\
\hline Sample & $\alpha$ & $\gamma$ & $\rho$ & $\sigma$ & $\theta$ \\
\hline LARGE & & & & & \\
\hline GH95: & & & & & \\
\hline I.C., $\theta=2$ & $.693(.009)$ & $.234(.023)$ & $.073(.005)$ & $.862(.037)$ & 2 \\
\hline SMALL & & & & & \\
\hline GH95: & & & & & \\
\hline I.C., $\theta=2$ & $.691(.007)$ & $.255(.07)$ & $.123(.029)$ & $.856(.032)$ & 2 \\
\hline
\end{tabular}

Table $2 \mathrm{a}$

\footnotetext{
${ }^{36}$ For the estimation, we recomputed $W$ using the simulation method described above.
} 


\begin{tabular}{|l|l|l|l|l|l|}
\hline & \multicolumn{5}{|l|}{ Reduced Form Estimates } \\
\hline Sample & $a_{1}$ & $a_{2}$ & $\operatorname{sc}\left(\frac{I}{k}\right)$ & $\operatorname{std}\left(\frac{\pi}{k}\right)$ & $\bar{q}$ \\
\hline LARGE & & & & & \\
\hline GH95: & .027 & .124 & .4 & .25 & 3 \\
\hline I.C., $\theta=2$ & .048 & .129 & .178 & .24 & 3.07 \\
\hline SMALL & & & & & \\
\hline GH95: & .056 & .2 & .4 & .25 & 3 \\
\hline I.C., $\theta=2$ & .064 & .2 & .078 & .251 & 2.98 \\
\hline
\end{tabular}

Table $2 b$

It is important to note that our exercise does not make use of an auxillary model to impose differences in firm size. Rather, we let the data tell us whether there are significant economic differences between large and small firms by doing separate estimation exercises for different subsets of empirical results. As before, our inputs to the process are the moments we wish to match and our output is the same set of moments (approximately matched) and the corresponding estimated parameters.

This exercise is fairly successful. We are able to match the differential responses of investment to cash flow coefficients which is a crucial element of the financial frictions empirical literature. The estimation procedure does this by finding a slightly smaller adjustment cost parameter $(\gamma)$ for large firms and a larger serial correlation of shocks for small firms. To the extent that current profits are informative about future profit opportunities, the higher 
estimate of $\rho$ for smaller firms is consistent with the increased responsiveness of investment to profit flows $\left(a_{2}\right)$ in the reduced form regressions reported in Table $2 \mathrm{~b}$. Another interesting characteristic of these results is that the estimation procedure finds the same concavity of profits for the two sets of firms, basically unchanged from the one obtained when matching the full sample results.

Given these parameter estimates it is not difficult to generate size differences across firms. One could augment the production process by incorporating some measure of managerial ability into the production function. The induced differences in productivity would create additional size differences but do not change the estimated structural parameters very much. ${ }^{37}$

Estimates of $(\alpha, \gamma, \theta)$

As a final exercise, we focus jointly on the curvature of the profit and the cost of adjustment function. Instead of forcing the adjustment function to be quadratic (i.e. setting $\theta=2$ in (5)), we allow the curvature of the adjustment cost function to be determined by the data. We proceed as above by finding the values of these parameters that minimize $J(\Theta)$ where $\Theta=(\alpha, \gamma, \rho, \sigma, \theta)$. From here it is quite clear that the model with quadratic costs is not a bad specification: the estimated value of $\theta$ is quite close to $2 .{ }^{38}$. The other parameter estimates, not surprisingly, remain relatively unchanged.

\footnotetext{
${ }^{37}$ This results we obtain by simulation of a model where we vary the mean of the profitability shock A to mimic differences across firms. While these changes in profitability clearly influence the size of the firm, they have relatively little effect on the reduced form estimates and moments calculated from the simulated data, as in Table 2.

${ }^{38}$ Abel-Eberly [1999] report a curvature estimate such that the marginal adjustment cost function is convex as do Barnett-Sakellaris [1999].
} 


\section{Conclusions}

Our model can produce regression results very close to those obtained in empirical studies based upon the $Q$ theory model. In stark contrast to the conclusions reached in those studies, our model does not contain any capital market imperfections. Instead, it differs from the standard model by adding market power and so moving away from the linear-quadratic structure generally taken as given in those exercises. Thus, the statistical significance of profit rates in the standard $Q$ investment regression may not reflect capital market imperfections.

Additional insights into these competing models can be obtained by looking explicitly at the implications of a model with borrowing constraints. Apparently, there has been little systematic study of the alternative model to determine whether the rejections of the basic $Q$ model could reflect capital market imperfections. One exception is Gomes [1998] who introduces a finance cost for external funds. Interestingly, he finds that capital market imperfections of this form will be summarized in marginal $Q$ and thus, under the right assumptions, captured by average $Q$ as well. This finding is, indirectly, additional support for our argument. ${ }^{39}$

Of course, there are many models of capital market imperfections to consider and also other formulations of adjustment costs beyond the quadratic specification that underlies the $Q$ model. Particularly appealing might be a model with non-convex market participation. This would model the conjecture that firm size is important for capital market imperfections and, more generally, to allow the constraints on firms to be endogenous. Further, this might

\footnotetext{
${ }^{39}$ In fact, Gomes [1998] says that "This provides support to the argument that the empirical success of cash flow augmented investment regressions is probably due to measurement error in q."
} 
tie in with evidence on the lumpiness of investment expenditures. 


\section{References}

[1] Abel, A. and O. Blanchard, "The Present Value of Profits and Cyclical Movements in Investments," Econometrica, 54 (1986), 249-73.

[2] Abel, A. and J. Eberly, "A Unified Model of Investment under Uncertainty," American Economic Review, 84 (1994), 1369-84.

[3] Abel, A. and J. Eberly, "Investment and q with Fixed Costs: An Empirical Analysis," mimeo, April 1999.

[4] Adda, J. and R. Cooper, "Balladurette and Juppette: A Discrete Analysis of Scrapping Subsidies," Journal of Political Economy, 108 (2000), 778-806.

[5] Barnett, S. and Sakellaris, P., "A New Look at Firm Market Value, Investment and Adjustment Costs," The Review of Economics and Statistics, (1999).

[6] Bond, S. and Meghir, C. "Dynamic Investment Models and the Firm's Financial Policy," Review of Economic Studies 61 (1994), 197-222.

[7] Caballero, R. "Aggregate Investment" NBER Working Paper \#6264, (1997).

[8] Caballero, R., E. Engel and J. Haltiwanger, "Plant-Level Adjustment and Aggregate Investment Dynamics," Brookings Papers on Economic Activity, 1995:2, 1-54.

[9] Caballero, R. and J. Leahy, "Fixed Costs: The Demise of Marginal Q". NBER Working Paper \# 5508, (1996)

[10] Chirinko, R., "Business Fixed Investment Spending," Journal of Economic Literature 31 (1993), 1875-1911 
[11] Cooper, R. and J. Haltiwanger, "On the Nature of the Capital Adjustment Process," NBER Working Paper \#7925, September 2000.

[12] Cooper, R., J. Haltiwanger and L. Power, "Machine Replacement and the Business Cycle: Lumps and Bumps, " American Economic Review, 89 (1999), 921-46.

[13] Cummins, J., Hassett, K.and S. Oliner, Investment Behavior, Observable Expectations and Internal Funds," mimeo, New York University, March 1999.

[14] Erickson, T. and T. Whited, "Measurement Error and the Relationship Between Investment and Q," Journal of Political Economy, 108 (2000),1027-57.

[15] Fazzari, S., Hubbard, R., and B. Petersen, "Financing Constraints and Corporate Investment," Brookings Papers on Economic Activity, 1 (1988), 141-95

[16] Galeotti, M and Schiantarelli, F., "Generalized Q Models for Investment," The Review of Economics and Statistics, 73 (1991), 383-92

[17] Gilchrist, S. and C. Himmelberg, "Evidence on the role of cash flow for Investment," Journal of Monetary Economics,36 (1995), 541-72.

[18] Gilchrist, S. and C. Himmelberg, "Investment: Fundamentals and Finance, "NBER Macroeconomics Annual (1998), 223-62

[19] Gomes, J. "Financing Investment," mimeo, Wharton School, University of Pennsylvania, (1998).

[20] Gourieroux, C. and A. Monfort, Simulation Based Econometric Methods, Oxford University Press, 1996. 
[21] Gourieroux, C., Monfort, A., and Renault, E. "Indirect Inference." Journal of Applied Econometrics 8, S85-S118, (1993).

[22] Gross, D. "The Investment and Financing Decisions of Liquidity Constrained Firms," mimeo, MIT, (1994).

[23] Hayashi, F., "Tobin's marginal Q and average Q: A neoclassical interpretation," Econometrica, 50 (1982), 215-24.

[24] Hayashi, F. and T. Inoue, "The Relationship between Firm Growth and Q with Multiple Capital Goods: Theory and Evidence from Panel Data on Japanese Firms," Econometrica, 59 (1991), 731-53.

[25] Hubbard, R., Kashyap, A. and T. Whited, "Internal Finance and Firm Investment, "Journal of Money Credit and Banking, 27 (1995), 683-701

[26] Lucas, R. and E. Prescott, "Investment Under Uncertainty," Econometrica, 39 (1971),659-81.

[27] Tauchen, G. "Finite State Markov-Chain Approximations to Univariate and Vector Autoregressions," Economics Letters, 20 (1986), 177-81.

[28] West, K., Comment on "Investment: Fundamentals and Finance", NBER Macroeconomics Annual (1998), 266-72

[29] Whited, T. "Debt, Liquidity Constraints, and Corporate Investment: Evidence from Panel Data." The Journal of Finance 47 (1992), 1425-1460. 
[30] Willis, J. "Estimation of Adjustment Costs in a Model of State-Dependent Pricing", mimeo, Boston University, December 1999. 